\title{
Reinforcement of cohesionless soil by multi-oriented geosynthetic inclusions
}

\author{
Shwetha Prasanna ${ }^{1 *}$, Reeya Khorjuvekar ${ }^{2}$, Samiksha Naik ${ }^{3}$ \\ ${ }^{1}$ Associate professor, Don Bosco College of Engineering, Fatorda, Goa \\ ${ }^{1,3}$ Students, Don Bosco College of Engineering, Fatorda, Goa \\ *shwethaprasanna@gmail.com
}

\begin{abstract}
Henry Vidal first introduced the concept of using strips, grids, and sheets for reinforcing soil masses. Since then, a large variety of materials such as steel bars, tire shreds, polypropylene, polyester, glass fibers, coir, jute fibers etc. have been widely added to the soil mass randomly or in a regular, oriented manner. In this investigation, a new concept of multi-oriented plastic reinforcement (hexa-pods), is discussed. A systematic and comprehensive laboratory tests were conducted on unreinforced and reinforced soil samples. Laboratory tests such as direct shear teat and California bearing ratio (CBR) test were analyzed on soil samples consisting of only soil samples, soil sample with random inclusion of hexapods and soil samples with layered inclusion of hexapods. From the results obtained through direct shear test it could be observed that cohesion value of both the soil sample has increased and the angle of internal friction has been decreased after reinforcing it with inclusions in both randomly and layered conditions. CBR test indicates that for same amount of compactive effort, both random and layered inclusions of hexapods show improvement in strength and stiffness. Random inclusions of hexapods give better resistance to penetration as compared to layered inclusions. The hexa-pods also changed the brittle behavior of unreinforced sand samples to ductile ones.
\end{abstract}

Keywords. Reinforced soil, hexapods, layered inclusion, random inclusion

\section{Introduction}

Reinforced soil has been widely used in geotechnical engineering applications such as construction of road and railway embankments, bridge abutments, stabilization of slopes, improvement of soft ground, in order to save the cost, ease of construction, reliability, and ability to improve the visual appearance. In addition, their excellent seismic performance and ability to withstand large deformations without structural distress make reinforced earth structures desirable. The concept of soil reinforcement started from early civilizations when they began to utilize straw and other such fibers to improve the strength and durability of dried bricks. Reinforcement of soil using tension elements mimics the behavior of plant roots and improves the strength and stability of soil layers. The addition of reinforcing elements was achieved in the following ways: - incorporating continuous reinforcement inclusions such as sheet, bar or strip within a soil mass in a well-defined pattern; randomly mixing discrete fibers with a soil fill. Early soil reinforcement techniques typically consisted of strips, grids, or sheets (woven or nonwoven geotextiles) placed horizontally in the soil. Later other types of reinforcement such as continuous filaments and randomly distributed small discrete inclusions in the form of fibers, rods, discs, shavings, meshes, and multioriented elements have been increasingly used.

Numerous studies have been performed on the conventional forms of reinforcements. B. Chandrasekaran, B.B. Broms and K.S. Wong (1989) have been attempted the planar form of reinforcement in sand using geosynthetic layers. In this paper, a new method for reinforcing soils is developed that involves the incorporation of multioriented geosynthetic elements (hexa-pods), randomly or in a layered manner within compacted or naturally deposited sand. The reinforceing elements were made of plastic, primarily polypropylene. A series of systematic triaxial compression tests was conducted on coarse, medium, and fine sands reinforced with multi-oriented plastic hexapods. Parametric studies were conducted by considering the volume ratio of hexa-pods $(\mathrm{Vr})$, orientation of hexa-pods, number of hexa-pods per layer, and the spacing of layers as variables. The 
results of the experiments indicate that reinforcing sand with hexa-pods resulted in an increase in their shear strength parameters. Shwetha Prasanna and Prasanna Kumar (2017) carried out a research on soil reinforcement using coconut shell ash as waste material for Indian soil. They observed by comparing all the results of Atterberg's limits maximum plasticity index, liquid limit was achieved at $2 \%$ and also maximum plastic limit was at $10 \%$ coconut shell ash reinforcement. Then regarding compaction, they concluded at $0.8 \%$ ash achieved maximum improvement of MDD and OMC. From direct shear test results, they concluded that angle of internal friction and cohesion was achieved at the range of 0.4 to $0.8 \%$. Shwetha Prasanna (2018) Utilized waste plastic shreds for stabilization of soil. In that research author added waste plastic shreds were in varying percentages like 2, 4, 6, 8, and $10 \%$ to the soil samples as a reinforcement material. For the first soil sample, there was a decrease in MDD, OMC, and cohesion and a slight increase in friction with an increase in the percentage of reinforcement. For the second sample also, almost the same results were obtained that means decrease in MDD, OMC, and cohesion and a slight increase in friction with increase in the percentage of reinforcement. The decrease in maximum dry density of soil must be due to low specific gravity of plastic shreds. Also, it has been observed that adding beyond $10 \%$ of plastic waste would not vary much in MDD value. Author concluded that the stabilized soil could be utilized for roadways, parking areas, site development projects, airports, and many other situations where subsoils are not suitable for construction.

In this paper, a new method for reinforcing soils is developed that involves the incorporation of multi oriented geosynthetic elements (hexa-pods), randomly or in a layered manner within a compacted or naturally deposited sand. A series of systematic triaxial compression tests was conducted on sands reinforced with multi-oriented plastic hexa-pods. Parametric studies were conducted by considering the volume ratio of hexa-pods ( $\mathrm{Vr}$ ), orientation of hexa-pods, number of hexa-pods per layer, and the spacing of layers as variables. The results of the experiments indicate that reinforcing sand with hexapods resulted in an increase in their shear strength parameters. Eyyub karakan, et.al (2018) conducted research on liquefaction behaviour of poorly graded sand reinforced with fibres. A progression of dynamic analyses was completed by performing cyclic triaxial tests on ineffectively evaluated sand examples. The sand was acquired in mass structure in an exhuming site in Izmir-Turkey. The liquefaction and stress-strain conduct of sand were examined in research centre triaxial tests performed on reconstituted examples. The liquefaction obstruction of ineffectively evaluated sand increments with an expansion in relative thickness. They concluded that fibre support could be an option in bringing down or disposing of the horizontal development of the sand brought about by liquefaction.

\section{Martials and Methodology}

Prototypes of multi- oriented considerations are utilized in the project. These prototypes comprise of six stems expanding radially from a focal centre point. These are made of a thermoplastic material. The geometry and measurements of multi-situated consideration are shown in Figure 1.

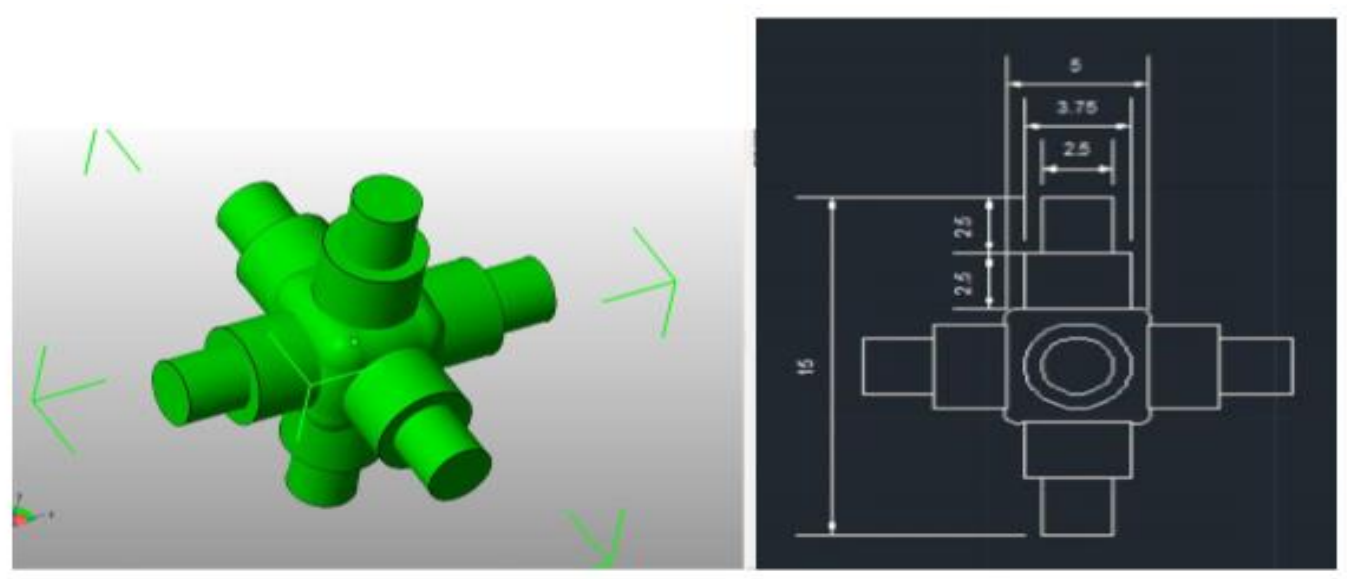

Figure 1: Hexapods 
Two soil sample were used in this study: A non-plastic, natural, poorly graded (zone 4) sand, obtained from south Goa, Colva area (latitude: $15^{\circ} 16^{\prime} 20.22^{\prime \prime} \mathrm{N}$ and longitude $73^{\circ} 53^{\prime} 1.41^{\prime \prime} \mathrm{E}$ ) (soil sample 1) and non-plastic, natural, poorly graded (zone 4) sand, obtained from north Goa, Mapusa area (latitude $15^{\circ} 35^{\prime} 60.00^{\prime \prime} \mathrm{N}$ and longitudinal $73^{\circ} 45^{\prime} 12^{\prime \prime} \mathrm{E}$ ) (soil sample 2).

The various laboratory test such as particle size distribution, bulk density, direct shear test and CBR tests were conducted on two soil samples.

Table 2. Different soil properties

\begin{tabular}{lll}
\hline & Sample 1 & Sample 2 \\
\hline $\begin{array}{l}\text { Specific } \\
\text { Gravity }\end{array}$ & 2.67 & 2.71 \\
Moisture & $12.57 \%$ & $14.88 \%$ \\
Content & & \\
Bulk Density & $1.58 \mathrm{~g} / \mathrm{cc}$ & $1.67 \mathrm{~g} / \mathrm{cc}$ \\
\hline
\end{tabular}

\section{Results and Discussion}

The results obtained were used to determine the improvement in soil parameters over unreinforced soil samples. Cohesion intercept increases with increasing hexapods inclusions for both sand samples of randomly and layered reinforced conditions. And also, the cohesion intercept rising rate of the randomly and layered reinforced sand is almost same in both samples. The comparison of bar chart (Figure 2) of direct shear test shows that, cohesion of sample 1 has increased by $0.13 \mathrm{~kg} / \mathrm{cm}^{2}$ and by $0.095 \mathrm{~kg} / \mathrm{cm}^{2}$ for random and layered inclusions respectively. Cohesion of sample 2 has increased by $0.065 \mathrm{~kg} / \mathrm{cm}^{2}$ and $0.08 \mathrm{~kg} / \mathrm{cm}^{2}$ for random and layered inclusions respectively.

It can be observed that the angle of internal friction has been decreased for both sand samples (Figure 3 ) in both randomly and layered conditions. The friction angle changes from $34^{\circ}$ for unreinforced sand to $29^{\circ}$ and $30^{\circ}$ by adding inclusions randomly and layered reinforced sand respectively for sample 1 and $33^{\circ}$ for unreinforced sand to $30^{\circ}$ and $28^{\circ}$ by adding inclusions randomly and layered reinforced sand respectively for sample 2 . Soil-inclusion friction interaction depends mainly on the exten sibility of the inclusions. In this study, both samples showed a favourable response to inclusions reinforcement.

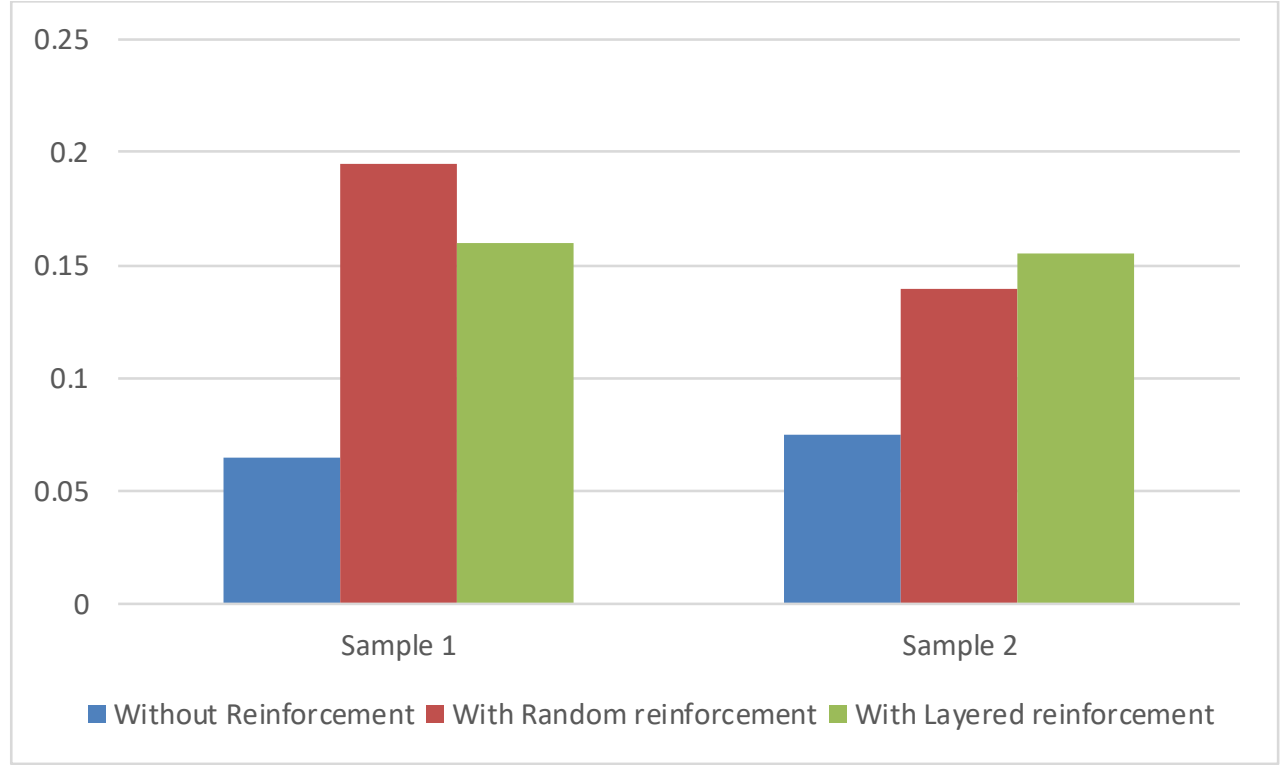

Figure 2: Comparison of cohesion values of two soil samples 


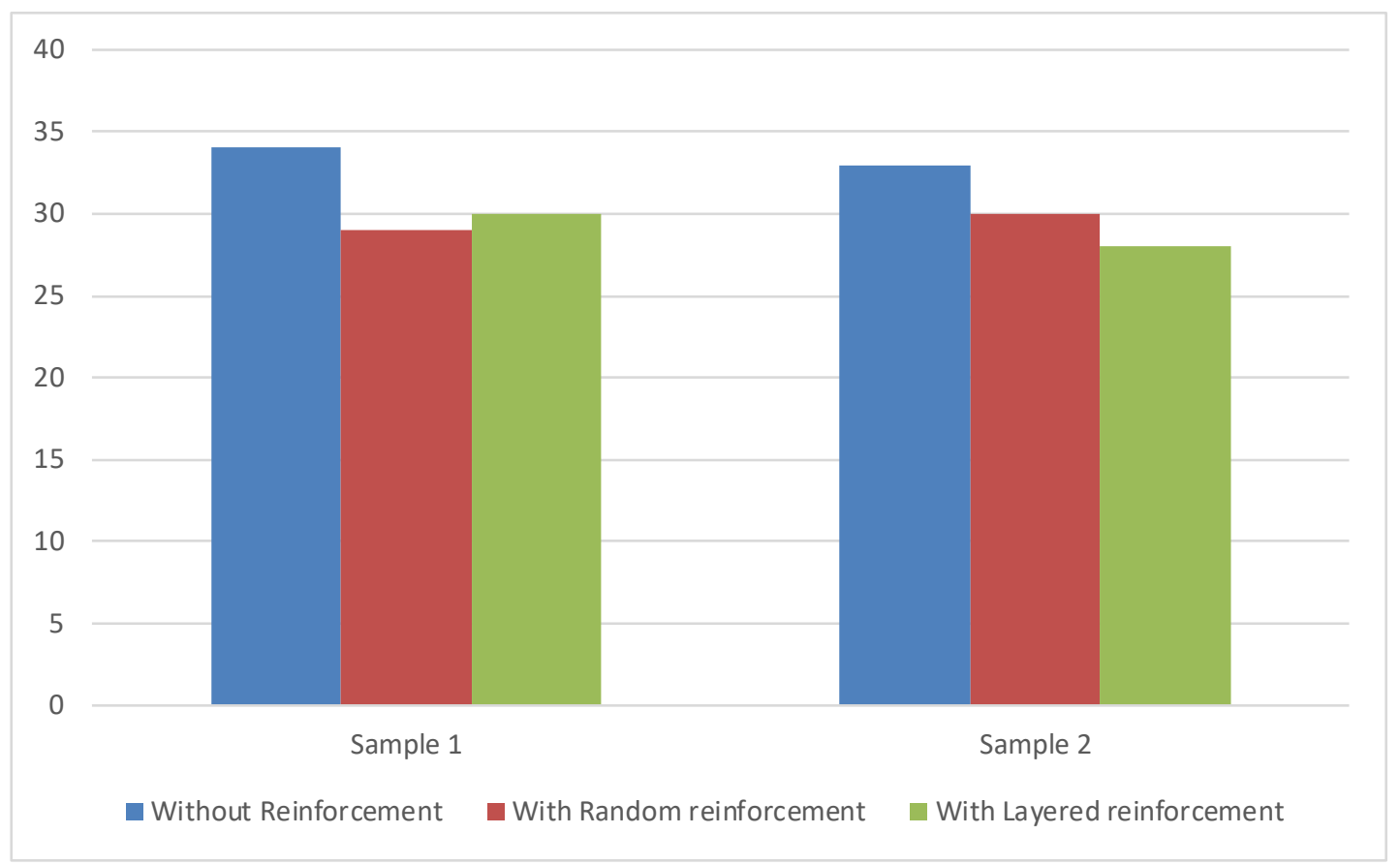

Figure 3: Comparison of friction values of two soil samples

The value of cohesion intercept of soil increases with increase in hexapods content as an inclusion. However, the angle of shearing resistance or friction does not change significantly with hexapods content. These observations might be due to the fact that the randomly and layered distributed inclusions act as a special three dimensional network to interlock soil particles to form a unitary coherent matrix and restrict any displacements, thus resulting in increased cohesion, but the individual hexapods inclusions might not have discernible effect on the microstructure of soil, thus not affecting the angle of friction of soil. (Tang et.al 2007b, Zaimoglu and Yetimoglu, 2012).

The CBR is a measure of resistance of a material to penetration of standard plunger under controlled density and moisture conditions. The effectiveness of inclusion of randomly and layered distributed hexapods in sandy soils for improving the CBR values is investigated through an experimental investigation. This paper describes the load penetration response obtained from CBR test s performed on both sand samples. The CBR values of both sands increase significantly due to inclusion of randomly and layered distributed hexapods. The comparison of bar chart (Figure 4) of CBR test shows the results such that for sample $1, \mathrm{CBR}$ value at $2.5 \mathrm{~mm}$ for random and layered inclu sion s has been increased by $13.87 \%$ and $6.57 \%$ respectively. CBR value at $5 \mathrm{~mm}$ for random and layered inclusions were $12.17 \%$ and $8.28 \%$ respectively. For Sample 2, CBR value at $2.5 \mathrm{~mm}$ for random and layered inclusions has been increased by $16.79 \%$ and $10.22 \%$ respectively. CBR value at $5 \mathrm{~mm}$ for random and layered inclusions were $13.14 \%$ and $9.73 \%$ respectively. The CBR tests indicated that the CBR values increased with increased hexapods content. However, the increase in CBR was not pronounced for hexapods contents greater than a certain value. 


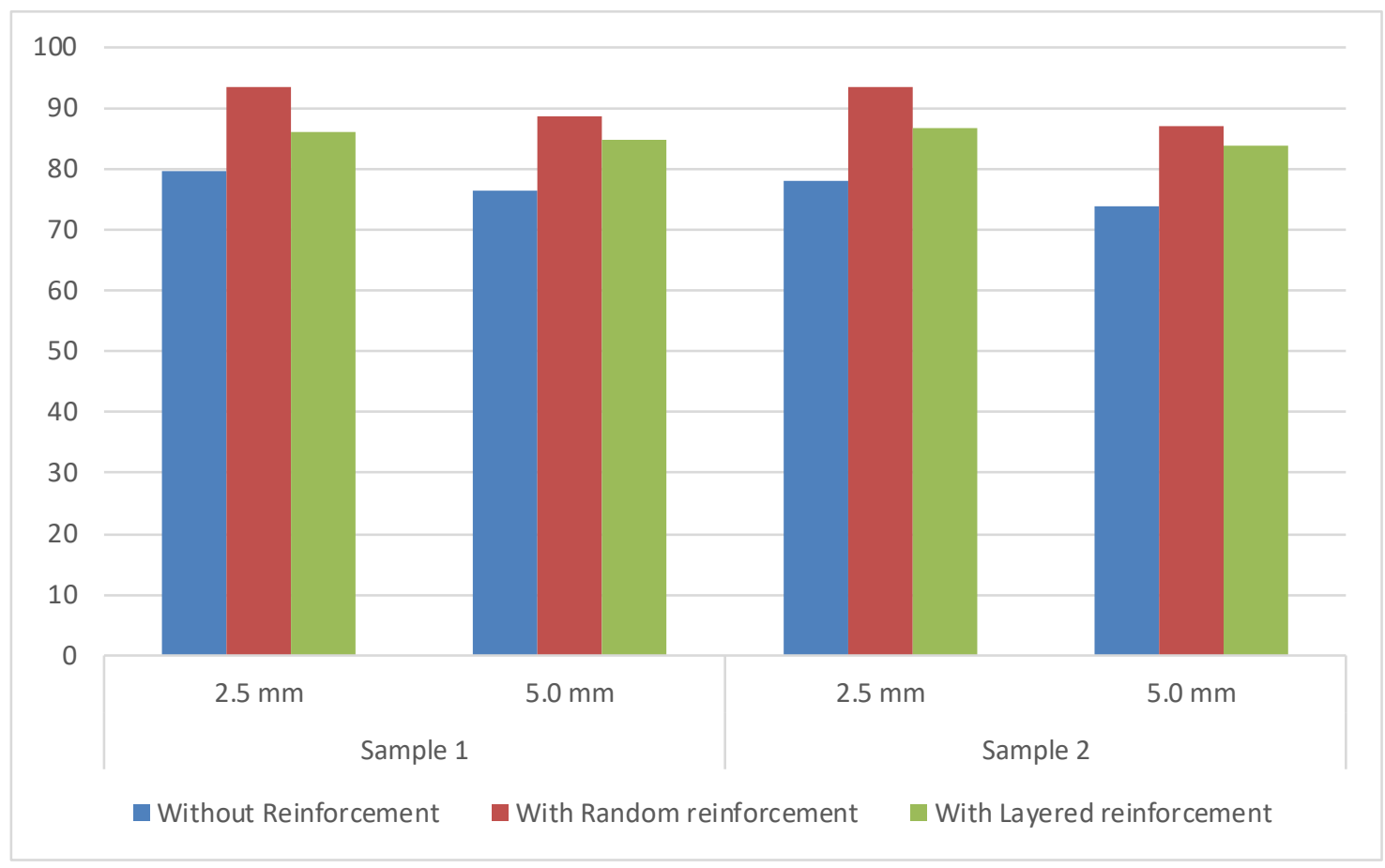

Figure 4: Comparison of CBR values of two soil samples

\section{Conclusions}

From the results obtained through direct shear test it could be observed that cohesion value of both the soil sample has been increased and the angle of internal friction has been decreased after reinforcing it with inclusions in both randomly and layered conditions. These observations might be due to the fact that the randomly and layered distributed inclusions act as a special three dimensional network to interlock soil particles to form a unitary coherent matrix and restrict any displacements, thus resulting in increased cohesion, but the individual hexapod inclusions might not have discernible effect on the microstructure of soil, thus not affecting the angle of friction of soil. CBR test indicates that for same amount of compaction and compactive effort, both randomly and layered inclusions of hexapods show improvement in strength and stiffness. Random inclusions of hexapods give better resist ance to penetration as compared to layered inclusions. Sample 2 gives increased percentage of CBR value as compared to sample 1. The CBR values increased with increased hexapods content. However, the increase in CBR was not pronounced for hexapods contents greater than a certain value. So randomly and layered hexapods inclusion showed to be reliable in industry projects as it helps to minimize the cost of projects.

\section{References}

B. Chandrasekaran, B.B Broms and K.S. Wong. "Strength of fabric reinforced sand under axisymmetric loading." Geotextile Geomembranes, Vol. 8(4), 1989, 293-310.

Evert C. Lawton, Milind V. Khire and Nathaniel S. "Reinforcement of soils by multi-oriented geosynthetic inclusions.” Journal of Geotechnical Engineering, Vol.119(2), 1993, 257-275.

A. P. Silva Dos Santos, N. C. Consoli and B. A. Baudet. "The mechanics of fibre reinforced sand." Journal of Geotechnical Engineering, Vol. 60(10), 2010,791-799.

A. Sahin Zaimoglu and Temel Yetimoglu. "Strength behaviour of fine-grained soil reinforced with randomly distributed polypropylene fibers." Geotech Geol. Engineering, Vol. 30, 2012, 197-203. 
Aqeel Al Adili, Rafig Azzam, Giovanni Spagnoli, and Joerge Schrader. "Strength of soil reinforced with fibre materials (Papyrus)." Journal of Soil Mechanics and foundation Engineering, Vol. 48(6), 2012, 241-247.

M. Harikumar1, N. Sankar1 and S. Chandrakaran. "Behaviour of cohesion less soil reinforced with three dimensional inclusions under plane strain conditions." Journal of Institutions of Engineers, Calicut, Kerala, Series A, Vol. 96(3), 2015, 223-228.

M. Harikumar, N. Sankar and S. Chandrakaran. "Response of sand reinforced with multioriented plastic hexa-pods." Journal of Soil Mechanics and Foundation Engineering, Vol. 52(4), 2015, 211217.

Shwetha P. and Prasanna Kumar N. "Soil reinforcement using coconut shell ash; A case study of Indian soil." Journal of Civil Engineering and Construction, Vol. 6, 2017.

Shwetha Prasanna. "Utilization of waste plastic shreds for stabilization of soil." Geotechnics for Transportation Infrastructure, 2018.

Eyyub Kerakan, Tugba Eskisar, and Selim Altun. "The liquefaction behavior of poorly graded sand reinforced with fibers." Journal of Advances in Civil Engineering, Vol. 114(4), 2018. 